Supplement of Atmos. Chem. Phys., 18, 9121-9145, 2018

https://doi.org/10.5194/acp-18-9121-2018-supplement

(C) Author(s) 2018. This work is distributed under

the Creative Commons Attribution 4.0 License.

(c) (1)

Supplement of

\title{
The Green Ocean: precipitation insights from the GoAmazon2014/5 experiment
}

Die Wang et al.

Correspondence to: Die Wang (diewang@bnl.gov)

The copyright of individual parts of the supplement might differ from the CC BY 4.0 License. 

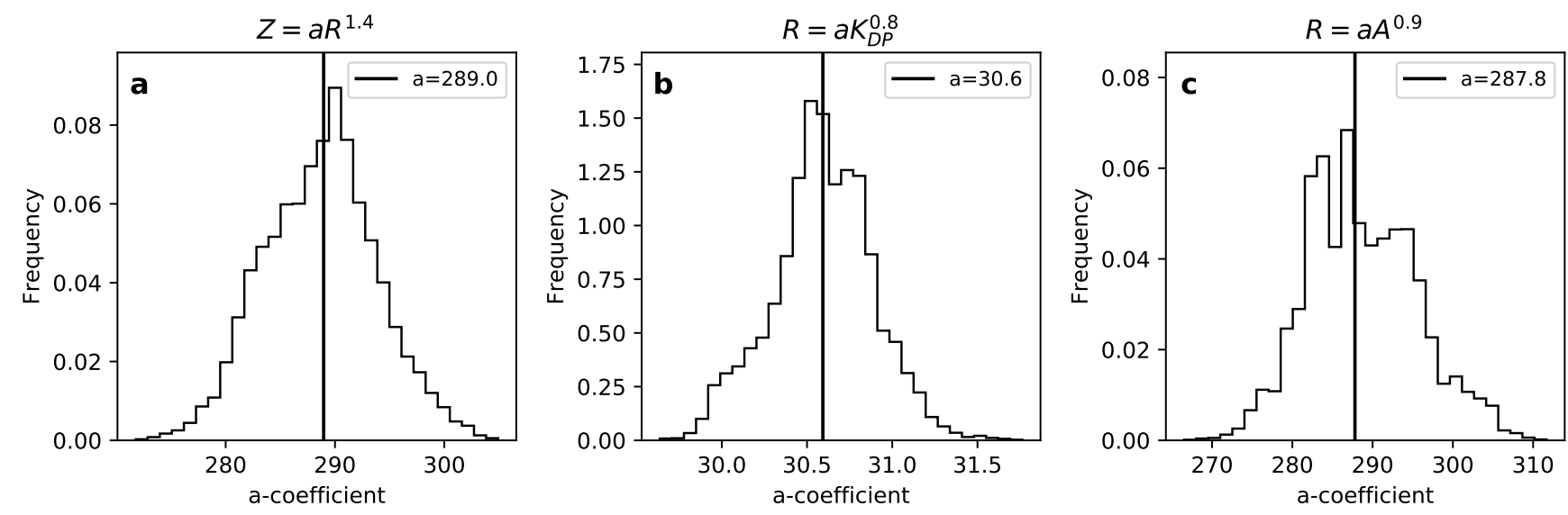

Figure 1S. Histograms for $a$-coefficient values from single parameter rainfall relationships (a) $R(Z)$, (b) $R\left(K_{D P}\right)$, and (c) $R(A)$, calculated using least square method under the assumption of a fixed $b$-coefficient from random sampling of half of the dataset (5000 times), for the $\mathrm{C}$-band wavelength. The black vertical lines represent the $a$-coefficient calculated based on the whole dataset. 

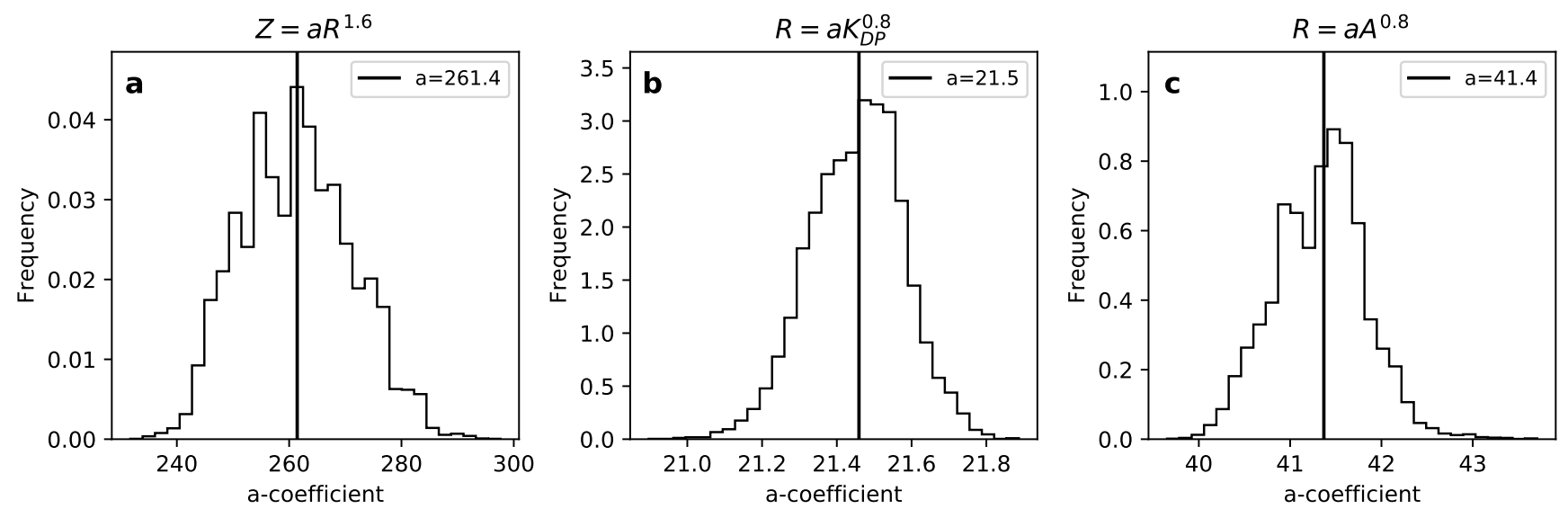

Figure 2S. Same as Figure 1S, but for the X-band wavelength. 

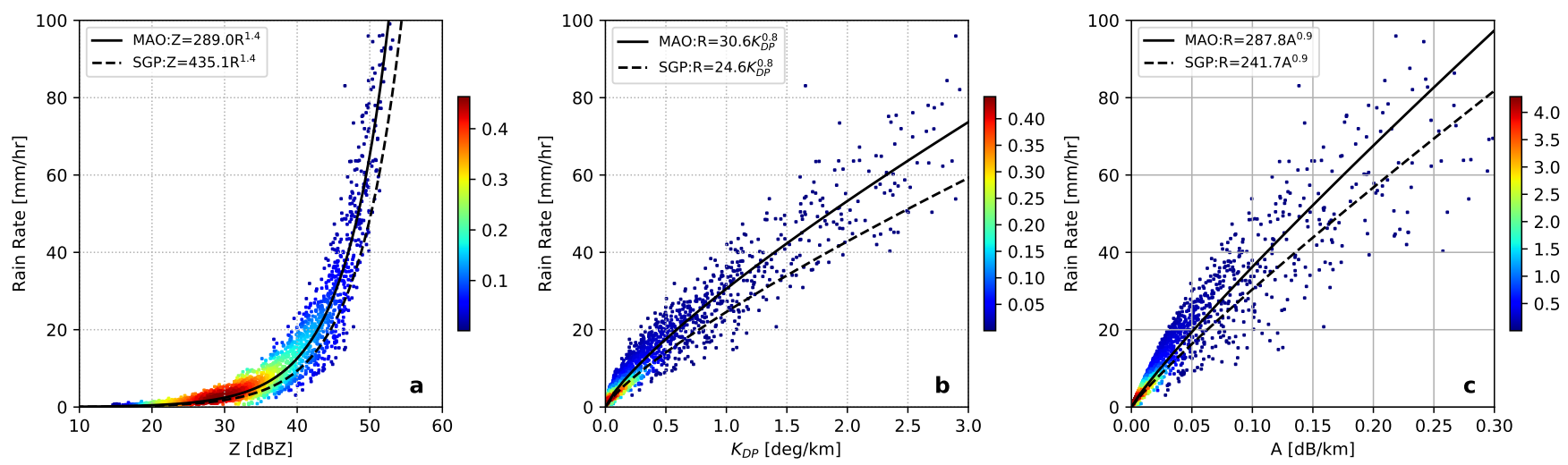

Figure 3S. Scatter plots of (a) $Z$, (b) $K_{D P}$, and (c) $A$ versus rain rate and overlaid associated relationship fits using least square method for Amazon (MAO, solid lines) and SGP-Oklahoma (SGP, dashed lines) sites, for the C-band wavelength. Density is shown in color. 

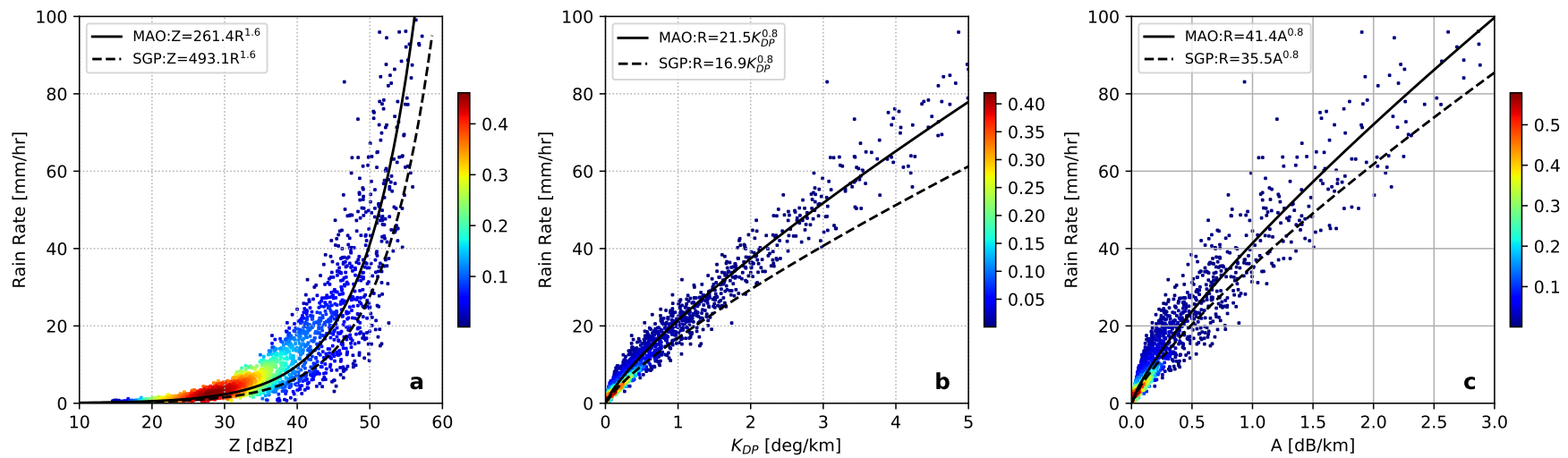

Figure 4S. Same as Figure 3S, but for the X-band wavelength. 

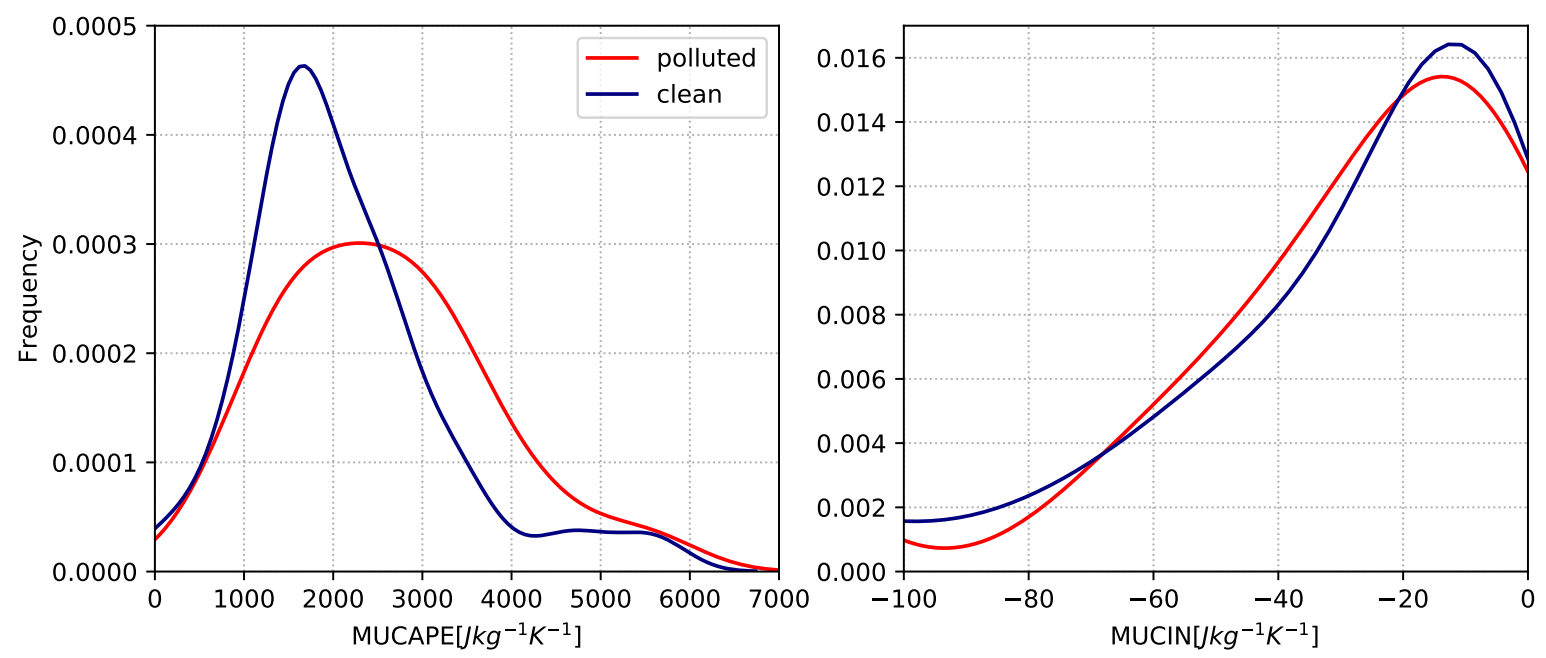

Figure 5S. Histograms of MUCAPE and MUCIN for polluted and clean cases. 

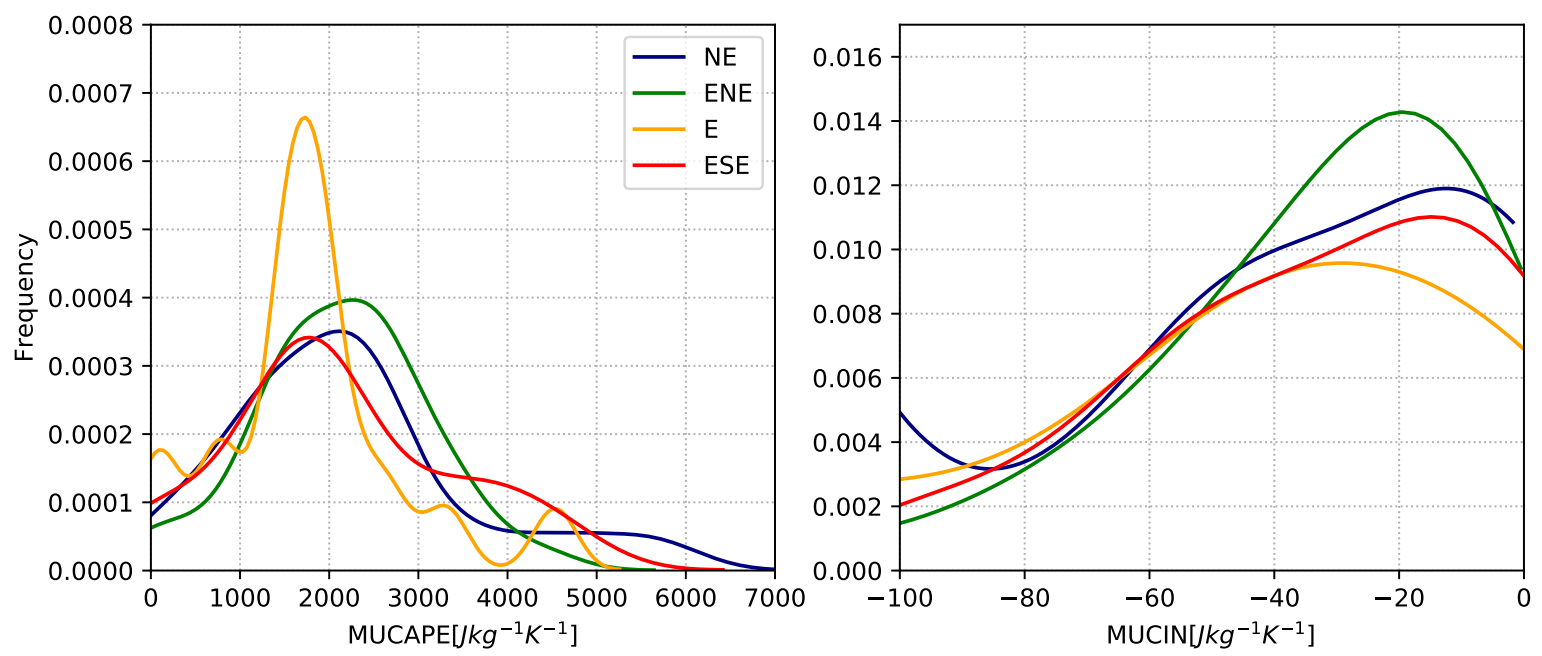

Figure 6S. Histograms of MUCAPE and MUCIN for different wind directions. 
Table 1S. Total convective precipitation and convective fraction for the GoAmazon2014/5 campaign for the cumulative dataset All, Wet, Dry and Transitional seasons. Additional breakdowns for proxy deep convection $(\mathrm{ETH}>9 \mathrm{~km})$ and congestus $($ ETH $<9 \mathrm{~km})$ clouds. Values are estimated according to segregations following BR methods, a hybrid BR/TM combination, the RWP classification, and a simple rainfall rate $R>10 \mathrm{mmhr}^{-1}$ threshold.

\begin{tabular}{llllll}
\hline & & BR & BR/TM & RWP & R>10 mmhr \\
\hline \multirow{2}{*}{ Total convective } & $>9 \mathrm{~km}$ & $1378.9(73.3)$ & $1584.0(84.2)$ & $1565.7(83.2)$ & $1480.7(78.7)$ \\
precipitation [mm] & $<9 \mathrm{~km}$ & $765.3(75.6)$ & $838.3(82.8)$ & $820.7(81.0)$ & $801.2(79.1)$ \\
(Convective & Wet season & $613.5(70.7)$ & $745.7(85.9)$ & $745.1(85.8)$ & $679.5(78.3)$ \\
fraction [\%]) & Dry season & $232.7(85.7)$ & $245.2(90.3)$ & $255.5(94.1)$ & $240.6(88.6)$ \\
& Transitional season & $482.1(69.8)$ & $554.2(80.2)$ & $551.0(79.7)$ & $536.2(77.6)$ \\
\hline
\end{tabular}

